\title{
Thyrotoxicosis in Nigeria-a study of forty-six patients
}

\author{
E. O. Olurin \\ F.R.C.S.E., F.R.C.S. \\ Department of Surgery, University College Hospital, Ibadan, Nigeria
}

\begin{abstract}
Summary
In a review of 874 Nigerian patients with various types of thyroid gland disorders, forty-six patients were found to be thyrotoxic $(5 \cdot 3 \%)$, supporting the common observation of many authors that thyrotoxicosis is rarer in the African than in Europe and North America where thyrotoxicosis accounts for $20-50 \%$ of all thyroidectomies. The incidence of thyrotoxicosis is higher in the female than male though there is a higher proportion of males in this series than in the United Kingdom. There is a higher incidence of secondary thyrotoxicosis than has been reported elsewhere.

The clinical features of hyperthyroidism in the Nigerian are no different from those reported in other countries, though our patients tend to report rather late. Primary thyrotoxicosis occured a decade earlier in this series than in Britain. Two of the forty-six patients had adenocarcinoma of the thyroid although only in twenty-seven patients was thyroid tissue available for histological examination. Laboratory investigations were essential in borderline cases, especially estimation of the PBI in those with multinodular goitres.
\end{abstract}

The standard methods of treatment by antithyroid drugs, ${ }^{131}$ I and surgery were employed with immediately satisfactory results, though the follow-up was so poor that it is impossible to evaluate the late effects of treatment.

\section{Introduction}

It is generally accepted that the indicence of thyroid disease is subject to geographic variation. Thyrotoxicosis is rare in the African (Blacklock, 1925; de Smet, 1954; Kihn, 1957). Trowell (1960) in his 29 year's service in East Africa reported only two cases of thyrotoxicosis. In Southern Rhodesia, Gelfand (1962) reported one case of primary thyrotoxicosis. Patel (1962) reported a series of five cases in Uganda and Wright reported eight cases from Kenya in 1967. There has also been a number of reports from Nigeria. Davey \& Ogunlesi (1963) described seven cases in Ibadan. Adesola (1968) reported seven cases in Lagos, Nigeria. The purpose of this study is to review all cases of thyrotoxicosis seen in a large teaching hospital in Nigeria with the aim to determine the characteristics and the problems of this disease as seen in this community. It is hoped that the analysis of the largest series, so far, from Africa will supply sufficiently educative and statistically significant data and illustrate the points of differences and similarities with thyrotoxicosis as seen in other lands.

\section{Material and methods}

The University College Hospital in Ibadan is the largest and oldest teaching hospital in Nigeria Since its inception in 1957 it has served practically the whole country until newer teaching hospitals were established less than 10 years ago. Naturally, a vast majority of the patients came from areas nearer the hospital. All patients with any type of thyroid disease seen and treated in the hospital from 1957 to 1970 were reviewed. The hospital records, viz. casenotes, operation and histological records and chemical pathological reports were studied in detail. A thorough prosepctive study of ten patients was carried out over a period of 5 years. Only cases with adequate information in their case-notes and those studied prospectively were included. Thyrotoxic patients who were diagnosed solely clinically and who, on retrospective review, satisfied Wayne's diagnostic index were included. Patients with a clinical diagnosis of thyrotoxicosis which was supported by special thyroid function laboratory tests were also included. Non-Nigerians were not included in this study. Children under the age of 5 years were excluded from this series. The follow-up of some patients was carried out personally. A few defaulting patients were traced to their homes for the purpose of this study.

\section{Results}

\section{Incidence}

In the 14-year period between 1957 and 1970, about 1000 patients with all varieties of thyroid disease were treated in this hospital. There was a noticeable yearly increase in the number of new cases from about twenty in 1958 to just over 120 in 1970 
with an annual average of about seventy new patients. Out of the 1000 patients, 874 had sufficiently adequate information to form the basis of this study. Thyrotoxicosis was the final diagnosis in forty-six of 874 patients, an incidence of $5.3 \%$. The age of the patients ranged from 8 to 70 years with a peak in the third and fourth decade. There were thirty-six females and ten males giving a ratio of $3.6: 1$. Table 1 shows the age and sex distribution, and it also shows that the female predominates in all age groups except at the extremes of life when the numbers were too few to be significant.

TABLE 1. Age and sex distribution in forty-six patients with thyrotoxicosis

\begin{tabular}{|c|c|c|c|c|c|c|c|c|c|}
\hline \multirow{2}{*}{$\begin{array}{c}\text { Age } \\
\text { (year) }\end{array}$} & \multicolumn{2}{|c|}{ Sex } & \multicolumn{3}{|c|}{ Primary } & \multicolumn{3}{|c|}{ Secondary } & \multirow{2}{*}{$\begin{array}{l}\text { Grand } \\
\text { total }\end{array}$} \\
\hline & $\mathbf{F}$ & $\mathbf{M}$ & F & $\mathbf{M}$ & Total & F & $\mathbf{M}$ & Total & \\
\hline $5-10$ & 2 & - & 2 & - & 2 & - & - & - & 2 \\
\hline $11-20$ & 5 & 2 & 5 & 2 & 7 & _- & - & - & 7 \\
\hline $21-30$ & 10 & 2 & 8 & 1 & 9 & 2 & 1 & 3 & 12 \\
\hline $31-40$ & 8 & 3 & 3 & 3 & 6 & 5 & - & 5 & 11 \\
\hline $41-50$ & 7 & 1 & 2 & - & 2 & 5 & 1 & 6 & 8 \\
\hline $51-60$ & 4 & - & - & - & - & 4 & - & 4 & 4 \\
\hline $61-70$ & - & 2 & - & 1 & 1 & - & 1 & 1 & 2 \\
\hline Total & 36 & 10 & 20 & 7 & 27 & 16 & 3 & 19 & 46 \\
\hline
\end{tabular}

\section{Clinical features}

The duration of thyrotoxic symptoms varied from 3 months to about 2 years. There was a history of pre-existing goitre in nineteen patients, the duration of the goitre varying from 4 to 35 years before the onset of toxicity. The symptomatology included loss of weight, increased appetite, excessive sweating, heat intolerance, protruding eyes, diarrhoea, palpitation, nervousness and irritability, tiredness, difficulty in breathing especially on exertion, polyuria, insomnia and amenorrhoea. There were seven severe cases including one neglected patient in very severe drug-resistant thyrotoxicosis who died some days after admission. The signs included the presence of visible and palpable goitre, bilateral exophthalmos, fine to gross tremours of the hands, warm moist hands, tachycardia during sleep, bruit over the gland and auricular fibrillation. Table 2 gives a detailed analysis of the symptoms and signs and the percentage incidence of each feature. There were twenty-seven patients with primary thyrotoxicosis: twenty-five had diffuse goitres and two had no goitres at all (Fig. 1). Nineteen patients had secondary thyrotoxicosis with pre-existing multinodular goitres (Fig. 2). Exophthalmos occurred in $81 \%$ of primary and $42 \%$ of secondary thyrotoxic patients. It was bilateral in all cases. Four patients with secondary thyrotoxicosis had auricular fibrillation and were in congestive heart failure.

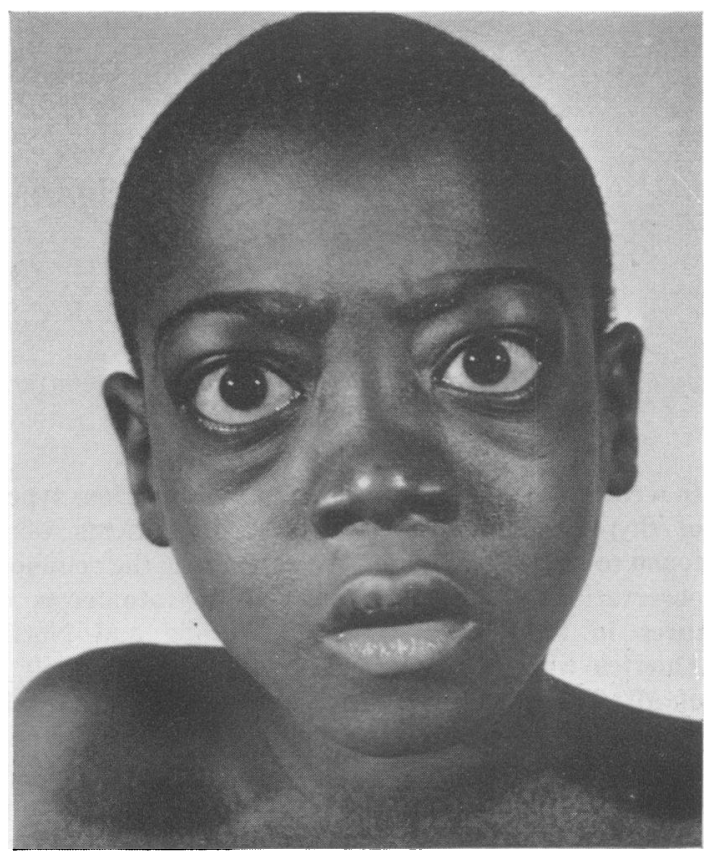

FIG. 1. Primary exophthalmic thyrotoxicosis in a boy of 11 years. The thyroid gland was only very slightly enlarged.

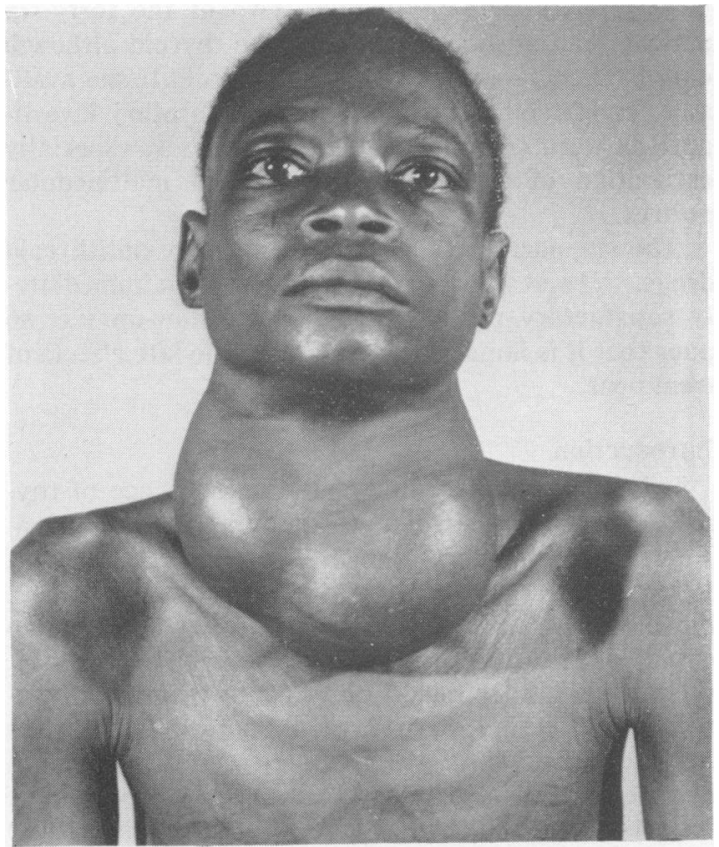

FIG. 2. Secondary thyrotoxicosis in a huge multinodular goitre with extensive calcification. Note the moderate exophthalmos. 
Two patients had follicular carcinoma with thyrotoxicosis. One of them was an unexpected histopathological finding in one of the nodules of a multinodular goitre. It was neither a 'cold' nor 'hot' nodule in the scintigram. The other was a 47-year-old woman who presented in 1963 with clinical simple nodular goitre. At operation the right lobe was enlarged and nodular but the left was visually and palpably normal, A right lobectomy and biopsy of the left lobe were performed. Both showed 'non malignant foetal adenoma' features. She was next seen again in 1970 with severe exophthalmic thyrotoxicosis and osteolytic thyroid carcinomatous deposits in the skull and ribs (Fig. 3). The left lobe was, in 1970, slightly enlarged and nodular; both this lobe and the bone deposits took up radio-active iodine ( $\left.{ }^{131} \mathrm{I}\right)$. There was no 'cold area' in the left lobe scintigram.

\section{Investigations}

The basal metabolic rate (BMR) was determined in eight patients in the earlier part of the period under consideration. Thyrotoxicosis was confirmed in all the patients. Serum protein-bound iodine (PBI) estimation was carried out in twenty-two patients and it was elevated in nineteen patients $(86 \%)$, and

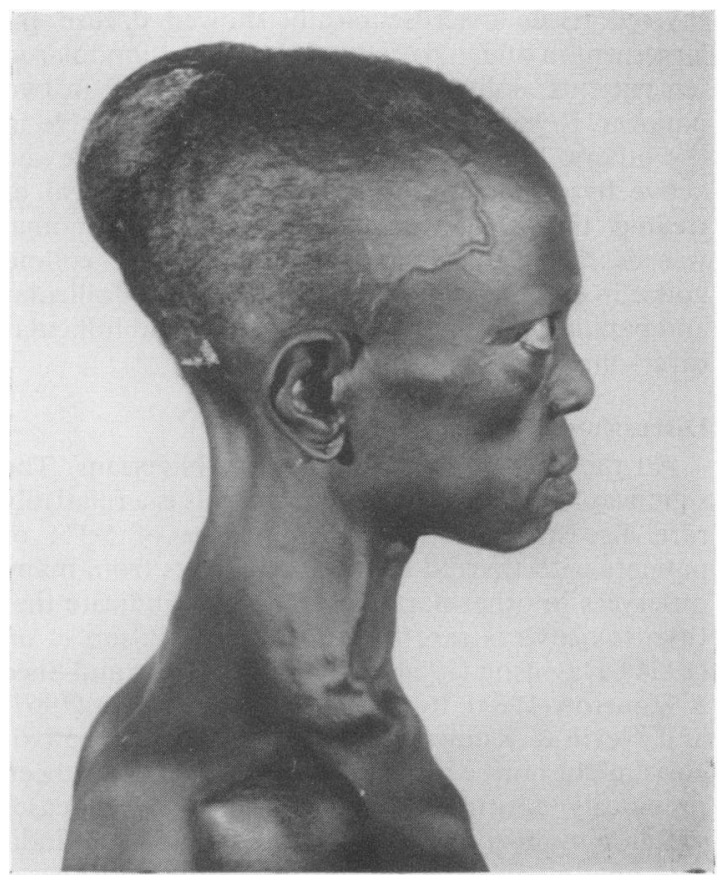

FIG. 3. Secondary exophthalmic thyrotoxicosis in a patient with secondary carcinomatous deposits. Note the huge skull deposit. All the secondary deposits show active iodine uptake. within normal limits $(3 \cdot 15-9 \mu \mathrm{g} / 100 \mathrm{ml}$ for Nigerians) in three patients. The radio-active iodine $\left({ }^{131} \mathrm{I}\right)$ studies were carried out in twenty-five patients. The ${ }^{131}$ I uptake values were raised in twenty patients $(80 \%)$, and within normal values in five patients. In eleven patients both the PBI and ${ }^{131}$ I uptake values were raised to thyrotoxic levels. In one patient the PBI was normal and the ${ }^{131}$ I was raised. In another patient the PBI was elevated and ${ }^{131}$ I uptake was normal. The serum cholesterol values were within the normal range in twenty-four patients and below normal in five. The non-specific investigations included radiological studies of the neck and chest and, in one patient, skeletal survey. There was a softtissue shadow in the neck in the forty-four goitrous patients; the trachea was displaced laterally in twenty-four patients and compressed to varying degrees in eight patients. Calcification of the goitre was radiologically present in five patients, all of whom had moderate to large multinodular goitres. The patient with thyrotoxic carcinomatosis had osteolytic secondary deposits in the skull and ribs.

\section{Diagnosis}

The diagnosis of thyrotoxicosis was based solely on clinical assessment in ten patients. The clinical diagnostic index of Wayne was applied retrospectively to arrive at this figure. In another twenty-nine patients, the diagnosis of thyrotoxicosis was based on clinical and specific thyroid function tests. The BMR confirmed the clinical diagnosis in ten patients. The ${ }^{131}$ I uptake and the PBI together confirmed the clinical diagnosis in eleven patients. Where the clinical diagnosis was supported by either the PBI or ${ }^{131}$ I uptake values but not by both, thyrotoxicosis was accepted for the purpose of this study. In three patients with multinodular goitres there was no clinical suspicion of thyrotoxicosis at first attendance in the out-patients department but subsequent inpatient reviews and the laboratory results made it easier to diagnose thyrotoxicosis. Two patients were only diagnosed postoperatively when they developed severe thyroid crisis. The two patients had multinodular goitres of many years' duration.

The diagnosis of primary and secondary thyrotoxicosis was based on the retrospective analysis of thirty-one patients and prospective study of fifteen patients. Where there was definite evidence of a nodular goitre antedating the onset of thyrotoxic symptoms by at least 4 years, secondary thyrotoxicosis was accepted. All patients with secondary thyrotoxicosis had multinodular goitres and were mostly middle-aged or older (Table 1 ). The patients with primary thyrotoxicosis were younger people; they had a relatively shorter duration of symptoms, and twenty-five of the twenty-seven patients had goitres which appeared about the same time as the 
TABle 2. Symptoms and signs in forty-six thyrotoxic patients

\begin{tabular}{|c|c|c|c|c|c|}
\hline \multirow{2}{*}{ Symptoms } & \multicolumn{2}{|c|}{ No. of patients } & \multirow{2}{*}{ Signs } & \multicolumn{2}{|c|}{ No. of patients } \\
\hline & Primary (27) & Secondary (19) & & Primary (27) & Secondary (19) \\
\hline $\begin{array}{l}\text { Loss of weight } \\
\text { Excessive sweating } \\
\text { Increased appetite } \\
\text { Palpitation } \\
\text { Nervousness/irritability } \\
\text { Diarrhoea } \\
\text { Tiredness } \\
\text { Dyspnoea on effort } \\
\text { Insomnia } \\
\text { Polyuria } \\
\text { Amenorrhoea }\end{array}$ & $\begin{array}{l}20(74 \%) \\
19(70 \%) \\
18(67 \%) \\
17(63 \%) \\
17(63 \%) \\
12(47 \%) \\
11(41 \%) \\
5(19 \%) \\
5(19 \%) \\
4(15 \%) \\
2(7 \%)\end{array}$ & $\begin{array}{r}10(53 \%) \\
12(63 \%) \\
4(21 \%) \\
14(74 \%) \\
8(42 \%) \\
8(42 \%) \\
11(58 \%) \\
10(53 \%) \\
3(18 \%) \\
\text { Nil } \\
\text { Nil }\end{array}$ & $\begin{array}{l}\text { Goitre } \\
\text { Tremors of hands } \\
\text { Exophthalmos } \\
\text { Sleeping tachycardia } \\
\text { Warm moist hands } \\
\text { Bruit over goitre } \\
\text { Thyrocardiac }\end{array}$ & $\begin{array}{l}25(93 \%) \\
16(59 \%) \\
22(81 \%) \\
25(93 \%) \\
21(78 \%) \\
9(33 \%) \\
\quad \text { Nil }\end{array}$ & $\begin{array}{l}19(100 \%) \\
10(53 \%) \\
8(42 \%) \\
16(84 \%) \\
8(42 \%) \\
1(5 \%) \\
4(21 \%)\end{array}$ \\
\hline
\end{tabular}

symptoms. Their thyroid glands were diffusely enlarged, and relatively smaller in weight than those with secondary thyrotoxicosis. Exophthalmos occurred in both groups though twice as often in primary as in secondary thyrotoxicosis. Thyrocardiac disease occurred only in secondary thyrotoxicosis in this series (Table 2).

\section{Treatment with results}

Antithyroid drugs alone were used for treating sixteen patients. Propylthiouracil was exhibited for three and carbimazole for thirteen patients who had primary thyrotoxicosis. One of the latter group was being prepared for thyroidectomy but she failed to return for the operation, probably because she felt better! The immediate effects of the drugs were gratifying in fifteen cases but none of these patients reported for further assessment for more than 8 months. It was thus impossible to assess the longtime effects of the drugs. One of the patients proved uncontrollable and she died of severe thyrotoxicosis.

Three patients were treated with radio-active iodine; two were about 60 years of age and the third, a 35-year-old woman, had had two previous operations for recurrent goitrous thyrotoxicosis. None of them was seen in the follow-up clinics after 9 months.

Subtotal thyroidectomy was performed on fifteen primary and twelve secondary thyrotoxic patients. All except two patients had adequate pre-operative antithyroid drug preparation. The two exceptions escaped correct pre-operative diagnosis and both had a postoperative thyroid crisis. There was no operative mortality. The immediate postoperative results were satisfactory in so far as thyrotoxicosis was concerned. The postoperative follow-up was poor because none of the patients returned after 3 years. Seven patients were traced to their homes in various parts of the country 4-9 years after thyroidectomy. They were all clinically euthyroid.

The patient with thyroid carcinomatosis and thyrotoxicosis was treated with carbimazole and thyroxine, the latter being later replaced with thyroid extract.
She improved tremendously. The ideal treatment for her would have been ${ }^{131}$ I, but this was not available.

\section{Pathology}

The weight of the excised goitrous tissue in twentyseven patients varied considerably. It weighed under $100 \mathrm{~g}$ in seven patients; between 100 and $200 \mathrm{~g}$ in ten patients and between 200 and $300 \mathrm{~g}$ in four patients. The weight was between 400 and $600 \mathrm{~g}$ in four patients. In one patient the excised gland weighed $1200 \mathrm{~g}$ and in another it weighed $1750 \mathrm{~g}$. The weight of the goitre was not recorded in two patients. The excised thyroid tissue macroscopically showed diffuse en largement in fifteen patients and was multinodular in? ten patients; solitary nodules were recorded in two patients. Relevant information was not available in the others. Microscopically, fifteen patients showed active hyperplastic goitres with features typical of treated thyrotoxicosis. 'Active solitary adenoma' was described in two patients and nodular colloid goitre in eight patients. There was a mixed follicular and papillary carcinoma in one patient and follicular carcinomatosis in another.

\section{Discussion}

All the patients in this series are Nigerians. The significant finding is that thyrotoxicosis is a relatively rare disease in Nigeria, an incidence of $5.3 \%$ of patients with thyroid disorders. Reports from many observers in other parts of Africa also indicate that thyrotoxicosis is rare in the African: Wilson et al. (1954), Davidson (1954), Bowesman (1960) and Shee \& Houston (1963). Recently, however, Wright (1967) and Nevill \& Kunga (1969) indicate that thyrotoxicosis might not be as rare in the African as has been previously reported. Wright (1967) found eight cases within 6 months in Kenya although he did not indicate how many patients with other thyroid diseases he saw within that period. Thyrotoxicosis is much more common in Europe and North America where the incidence varies from 20 to $50 \%$ of all thyroidectomies according to Montgomery \& Welbourne 
TABLE 3. Incidence of thyrotoxicosis in several series of thyroid disorders

\begin{tabular}{|c|c|c|c|c|c|}
\hline \multicolumn{3}{|c|}{ United Kingdom } & \multicolumn{3}{|c|}{ Africa } \\
\hline Authors & $\begin{array}{l}\text { No. of } \\
\text { cases }\end{array}$ & $\%$ of total & Authors & $\begin{array}{l}\text { No. of } \\
\text { cases }\end{array}$ & $\%$ of total \\
\hline $\begin{array}{l}\text { Young \& Meachim (1964) } \\
\text { Till (1969) } \\
\text { Kennedy (1970) }\end{array}$ & $\begin{array}{l}313 \\
517 \\
163\end{array}$ & $\begin{array}{l}24 \cdot 4 \\
46 \cdot 5 \\
49\end{array}$ & $\begin{array}{l}\text { Patel (1962) } \\
\text { Davey \& Ogunlesi (1963) } \\
\text { Wright (1967) } \\
\text { Nevill \& Kungu (1969) } \\
\text { Kennedy (1970) } \\
\text { Present series }\end{array}$ & $\begin{array}{r}5 \\
7 \\
8 \\
17 \\
9 \\
46\end{array}$ & $\begin{array}{l}\text { Not given } \\
\quad " \\
\quad 7 \\
4 \\
5 \cdot 3\end{array}$ \\
\hline
\end{tabular}

(1963), Young \& Meachim (1964), Till (1965) and Kennedy (1970) (Table 3). The factors responsible for the low incidence of thyrotoxicosis in the African are not known, thought environmental and racial factors have been suggested by Trotter (1962) and Patel (1963).

Thyrotoxicosis, as a whole, has a peak ageincidence at 21-40 years in this series as shown by Table 1. When, however, primary is separated from secondary thyrotoxicosis, it becomes evident that the peak age-incidence for primary thyrotoxicosis is 21-30 years and the peak for secondary thyrotoxicosis is the 41-50 decade. The former is in agreement with the finding of Patel in Uganda. It is probably significant that the peak age-incidence in 1000 cases of all types of thyroid diseases seen in this hospital, in which $87 \%$ constitutes simple goitres, is $31-40$ years (Olurin et al., 1971). Primary thyrotoxicosis thus appears to occur a decade earlier in this series than in Britain, according to Young \& Meachim (1964). Thyrotoxicosis is commoner in the female than in the male but the male incidence appears to be higher in this series than in the European and American patients.

The symptoms and signs of thyrotoxicosis in many of these patients are so marked that there is no difficulty in the diagnosis. This is particularly so in primary thyrotoxicosis because patients do not, generally, seek medical advice in the early phase of illness in this community. In some patients with secondary thyrotoxicosis the clinical features are not always unequivocal. The picture is further complicated by the finding, in these patients, that many multinodular simple goitres in euthyroid patients take up iodine avidly. The bigger the goitre the higher the iodine uptake. Indeed they behave very much like endemic goitres (Stanbury, 1958). It is probably relevant to point out that the majority of patients with multinodular goitres and secondary thyrotoxicosisis live in areas where goitres are locally known to be endemic.

Thus, in mild secondary thyrotoxicosis occurring in multinodular goitres both the clinical assessment and radio-active uptake studies may not be of great help in diagnosis. The serum protein-bound iodine estimations, however, have provided values which give a more sensitive index of thyroid function irrespective of size in these mild cases. It would appear that a number of patients with secondary thyrotoxicosis are indeed cases of Basedow thyrotoxicosis. During the last 5-10 years there has been an improvement in the standard of living in many rural areas: the diet is better balanced, pipe-borne water is available in many areas, travelling is easier and illiteracy is gradually diminishing. It is therefore plausible to argue that the iodine content of food and water is gradually increasing in areas which had had a low iodine supply. More iodine is being made available to multinodular goitres, which show avid iodine uptakes under laboratory conditions. The large proportion of secondary thyrotoxicosis in this series is thus explained. On this basis, it is to be expected that the number of secondary thyrotoxic patients will increase in future if improvement in the standard of living continues in areas where simple multinodular goitre is common. In favour of this phenomenon is the fact that endemic thyrotoxicosis has been observed by Stewart and his co-workers (1971) following iodination of bread in Northern Tasmania which is known to be a goitrous area.

The association of thyrotoxicosis and carcinoma of the thyroid in two cases $(7 \%)$ in this series is interesting. Although it was once thought that thyrotoxicosis was a sort of insurance against carcinoma of the thyroid (Mean, 1948) yet in recent years there has been a number of reports on the occurrence of both diseases co-existing, as shown in Table 4. Thyroidectomy was performed in twentyseven of forty-six patients and only the excised goitrous tissues of these patients were subjected to histopathological examination. The rest of the patients had either antithyroid drugs or ${ }^{131}$ I therapy. It would not be known whether any of these contained carcinoma. It is thus possible that carcinoma of the thyroid occurring in thyrotoxic patients treated medically is being missed, and therefore the incidence of carcinoma in the thyrotoxic gland may be greater than has been found.

The management of thyrotoxicosis in this hospital does not differ significantly from that in practice 
TABLE 4. Incidence of association of thyrotoxicosis and thyroid cancer

\begin{tabular}{lcc}
\hline \multicolumn{1}{c}{ Authors } & $\begin{array}{c}\text { Total no. } \\
\text { of cases }\end{array}$ & $\begin{array}{c}\% \\
\text { incidence }\end{array}$ \\
\hline Leoutsakos (1963) & 362 & $0 \cdot 5$ \\
Olen \& Klinok (1965) & 2114 & $2 \cdot 5$ \\
Georgiadis, Leoutsakos \& Katsas & & \\
$\quad(1970)$ & 500 & $3 \cdot 8$ \\
Beahrs \& Sakulsky (1968) & 377 & $2 \cdot 0$ \\
Willis (1960) & 1348 & 1 \\
Kilpatrick, Blomfield \& Nea & 100 & 7 \\
$\quad$ (1957) & 46 & $7^{*}$ \\
\hline Present seiies & & \\
\hline
\end{tabular}

* $4 \%$ associated with carcinoma.

elsewhere (Riddell, 1965). But it is impossible to assess the late effects of any form of therapy because of the poor follow-up. This is a phenomenon which makes scientific assessment of the natural course of a disease and the effects of treatment almost impossible in this community. Many of the patients are poor peasants who live in distant rural areas and who have no relations to stay with in this largest city in Black Africa. Most cannot finance frequent visits to the hospital. It is no wonder then that once they feel relieved of their symptoms they cannot indulge in the luxury of further expensive and difficult journeys to the 'unfriendly city'. This is probably why very few patients are seen regularly in follow-up clinics a few years after the commencement of treatment. On the other hand, it is too expensive, difficult and time-consuming to carry out regular visits, however infrequent, to the homes of these patients.

\section{Conclusion}

Thyrotoxicosis is a rarer disease in Nigeria than in Europe and North America. There is a high incidence of secondary thyrotoxicosis in the multinodular goitre in this series, probably as a result of gradual improvement in the socio-economic situation of the patients, especially those from rural areas where goitre is known to be endemic. Thyrotoxicosis is four times as common in the female as in the male. It would appear that primary thyrotoxicosis occurs mostly in the third decade in the Nigerian patients but a decade later in Britain. Secondary thyrotoxicosis occurs predominantly in the fifth decade in this series. The Nigerian patients present with the same symptoms and signs of thyrotoxicosis as those recorded in other countries. It is not always possible to apply the standard modern laboratory investigations to all the patients regularly because of technical deficiencies and the inevitable delays in processing imported reagents and isotopes. However, the PBI values give a better indication of the thyroid gland function than the ${ }^{131}$ I uptake studies. This is particularly so in borderline cases of primary thyrotoxicosis and also in multinodular goitre of several years' duration with non-exophthalmic mild toxicity. In the latter patients, the ${ }^{131}$ I uptake values are not often helpful. Retrospective clinical diagnosis of hyperthyroidism by the application of Wayne's diagnostic index is quite easy in the established disease but very difficult indeed in the borderline cases. Wayne's method is best used in prospective studies if understood and faithfully but critically applied. The co-existence of hyperthyroidism and adenocarcinoma of the thyroid in two patients $(4 \%)$ in this series is a pointer and it deserves serious consideration in dealing with all thyrotoxic patients. The immediate effects of treatment with antithyroid drugs, ${ }^{131} \mathrm{I}$ and surgery are gratifying but the poor follow-up in this series does not allow full assessment of the late effects of these different methods of therapy.

\section{Acknowledgments}

I am grateful to all my colleagues who have looked after some of these patients. Professor Adadevoh of the Department of Chemical Pathology has been of great help in the investigations of these patients and for his help and advice to me personally. I owe much to $\mathrm{Mr}$ Odeyale for the excellent secretarial efforts.

The work is supported in part by the University of Ibadan Senate Research Fund and in part by a grant from the West African Medical Research Council.

\section{References}

Adesola, A.O. (1970) A study of thyrotoxicosis in Lagos? In: Tropical Surgery (Ed. by S. I. Schwartz, A. O. Adesola, E. A. Elebute and C. Rob). McGraw-Hill Book Co., London.

Bearhrs, O.H. \& Sakulsky, S.B. (1968) Surgical thyroidectomy in the management of exophthalmic goitre. Archives of Surgery, 96, 512.

BLACKLOCK, D.B. (1925) Endemic goitre and schistosomiasis in Sierra Leone. Transactions of the Royal Society of Medicine and Hygiene, 18, 395.

Bowesman, C. (1960) Surgery and Clinical Pathology in the Tropics. Livingstone, Edinburgh.

DaveY, W.W. \& Ogunlesi, T.O. (1963) Thyrotoxicosis in Nigeria. West African Medical Journal, 12, 174.

DavidSon, L.S.P. (1954) African journey. Lancet, i, 614.

DE SMET, M.P.(1954) Contribution à l'étude de la pathologie thyroidienne en Congo Belge. Annales de la Société belge de médecine tropicale, $34,47$.

Gelfand, M. (1962) Thyrotoxicosis in the African. Central African Journal of Medicine, 8, 123.

Georgiadis, N.J., Leoutsakos, B.G. \& Katsas, A.G. The association of thyroid cancer and hyperthyroidism. International Surgeon, 55, 27.

KENNEDY, J.S. (1970) Surgical goitre in Glasgow and Nairobi. East African Medical Journal, 47, 73.

KinN, R.B. (1957) Quoted by K. N. Patel. East African Medical Journal, 39, 600.

Kilpatrick, R., Blomfield, G.W., Nea, F.E. \& Wilson, G.M. (1957) Carcinoma of the thyroid: A review of 100 cases. Quarterly Journal of Medicine, 26, 209.

Leotsakos, B. (1963) Surgical treatment of thyrotoxicosis. Helliniki latriki, 32, 10.

Mean, J.H. (1948) The Thyroid and Its Diseases, 2nd edn. Lippincott Co., Philadelphia. 
Montgomery, D.A.D. \& Welbourne, R.B. (1963) Clinical Endocrinology for Surgeons. William Wilkins, Baltimore.

Nevill, G. \& Kungu, A. (1969) Goitre in Kenya. East African Medical Journal, 46, 598.

Olen, E. \& KlincK, G.E. (1965) Association of hyperthyroidism and thyroid cancer. In: Current Topics in Thyroid Research (Ed. by C. Cassano and M. Andreoli). Academy Press, New York and London.

Olurin, E.O., Itayemi, S.O., Oluwasanmi, J.O. \& Ajayi, O.O. (1972) The pattern of thyroid diseases in Nigeria. In preparation.

Patel, K.N. (1962) Thyrotoxicosis at Mulago Hospital. East African Medical Journal, 39, 600.

RIDDELL, V. (1965) The selection of patients for thyroidectomy. British Journal of Surgery, 52, 721.

SHEE, J.C. \& Houston, W. (1963) Thyrotoxicosis in Southern Rhodesia. Central African Journal of Medicine, 9, 267.

StaNBuRY, J.B. (1958) lodine metabolism and physiological aspects of endemic goitre. Bulletin of the World Health Organization, 18, 207.
Stewart, J.G., Vidor, G.I., Butterfield, I.H. \& Hetzel, B.S. (1971) Endemic thyrotoxicosis in Northern Tasmania. Australian and New Zealand Journal of Medicine, 3, 203.

TILl, A.S. (1965) Carcinoma of the thyroid. Proceedings of the Royal Society of Medicine, 58, 309.

Trotter, W.R. (1962) Diseases of the Thyroid, 1st edn. Blackwell Scientific Publications, Oxford.

Trowell, H.C. (1960) Non-infective diseases in Africa, 1st edn. Edward Arnold, London.

WAYNES, E. (1965) The assessment of thyroid function. British Journal of Surgery, 52, 717.

Willis, J. (1960) Studies in carcinoma of the thyroid gland. M.D. Thesis, Queen's University, Belfast, N. Ireland.

Wilson, D.C., GRundy, H.M., STeEl, R.W. \& EdDY, T.P. (1954) Goitre in Sierra Leone. Transactions of the Royal Society of Tropical Medicine and Hygiene, 48, 481.

Wright, C.I. (1967) Thyrotoxicosis in the African: Report of eight cases. East African Medical Journal, 44, 455.

Young, M.H. \& Meachim, G. (1964) Surgical pathology of thyroid disease. British Journal of Surgery, 51, 497. 